\title{
TRAFFIC MANAGEMENT FACILITIES USED AT INTERSECTION OF UKMERGĖS AND GELEŽINIO VILKO STREETS IN VILNIUS
}

\author{
Vidmantas Pumputis ${ }^{1}$, Giedrius Garbinčius ${ }^{2}$, Valentin Mironov ${ }^{3}$ \\ Department of Automobile Transport, Vilnius Gediminas Technical University \\ J. Basanavičiaus g.28 LT-03224Vilnius, Lithuania
E-mails: ${ }^{2}$ vidmantas.pumputis@vgtu.lt; ${ }^{2}$ giedrius.garbincius@vgtu.lt; ${ }^{2}$ valentin.mironov@stud.vgtu.lt
}

Vilnius, the capital and the largest city of Lithuania, is faced with serious traffic problems. The main streets of the city are overcrowded with traffic. Therefore, the effective ways to ease the congestion should be sought. The paper considers the problem of high traffic intensity and congestion at the intersection of two busy Vilnius streets. Research is based on the analysis of the data stored at the Vilnius Traffic Management Centre and the information obtained in the experimental investigation of traffic flows. All the collected data have been used in the traffic simulation program, to make some effective measures helping to increase traffic capacity of the considered intersection.

Keywords: traffic intensity, free flow, intersection, velocity

\section{Introduction}

For the past ten years, the traffic on Lithuanian roads has increased 2.4 times. The number of road vehicles in Lithuania in the period from 1998 to 2010 has increased from 1,145,879 to 1,954,592 units, while the number of passenger cars during the same period has grown from 920,373 to $1,554,270$ units and the number of private cars per 1000 residents has increased by nearly two times (from 260 to 479 units). Therefore, the number of accidents, vehicle time losses at junctions and the environmental pollution by exhaust gases and noise has also increased. At rush hours traffic jams are formed at junctions.

Transport system in Vilnius is a legacy of the Soviet planning system. At that time, it seemed reasonable to create a large living area in the northern and western parts of the city, and the industrial districts in its southern part. As a result, most of the inhabitants were going to the work areas and then back to the dormitory districts simultaneously. Over time, the quality of life has improved and the number of vehicles has grown. This led to the formation of large traffic flows. In the morning, most of the inhabitants travel from north to south, while, in the evening, they go back. Therefore, even high capacity roads are overloaded. Zi-You Gao et al. (2007) studied the influence of the traffic dynamics on the structural properties of the evolution network, and measure the probability distributions and scaling properties of the network. Authors found that the topological structure of the evolution network is strongly related to the traffic dynamics. Various traffic control models are presented in the article written by Evangelos Mitsakis et al. (2011). Authors focused mainly in identifying the differences between the use of STA and DTA models. B. S. Kerner (2002) in his article presented two phases in congested traffic: wide moving jam and synchronized flow. Author compared the free flow capacity with a wide moving jam and synchronized flow in congested traffic. G. Kotusevski and K.A. Hawick (2009) in their article presented traffic simulation packages used to help engineers simulate traffic networks. Traffic speed one of the basic variables that indicate the level of service of a road entity presented in the article written by Xin Pei et al. (2011). Prediction models for average speed and speed dispersion established using the simulation approach full Bayesian method. Jaesup Lee et al. (2012) presented a series of regression models to predict lane use distributions of individual lanes that could provide information monitoring traffic conditions and predicting when and how traffic breakdown occur from a given condition.

The aim of the work is to analyse the factors negatively affecting traffic and causing congestion at the intersection of Geležinio Vilko and Ukmergès Streets and, based on the results obtained, to offer some effective traffic management facilities to increase traffic capacity and safety of these streets. For this purpose, it is necessary to strengthen the selected weakest points. The weakest point is the intersection of Ukmergès and Geležinio Vilko Streets. 


\section{Measuring Traffic Intensity in Vilnius}

Traffic in Vilnius is rather heavy. All traffic information is accumulated by Vilnius Traffic Management Centre. This centre has both traffic control and surveillance systems.

The main control program is SITRAFFIC Server. This program monitors the system's work 24 hours a day and sends alerts to operators if the program records the damage.

The data comes to the program from traffic sensors installed at intersections. There are two types or sensors (see Figure 1): video detectors and inductive sensors. The video sensor (made by 'Traficon') is a camera detecting vehicles. A special program controlling video sensors defines their operation area and the direction of traffic intensity is determined. Inductive sensors operate on the principle of electromagnetic induction. An induction detector is installed in the pavement, and the car passing it generates an electromagnetic pulse. This pulse is transmitted to the program, which reads it as a vehicle. All the data obtained from the sensors are sent to the main server where they are processed and stored.

The data entered into the program of the selected sensors during daytime from November 5, 2011 until November 11, 2011 were entered into the program database and used in this work.
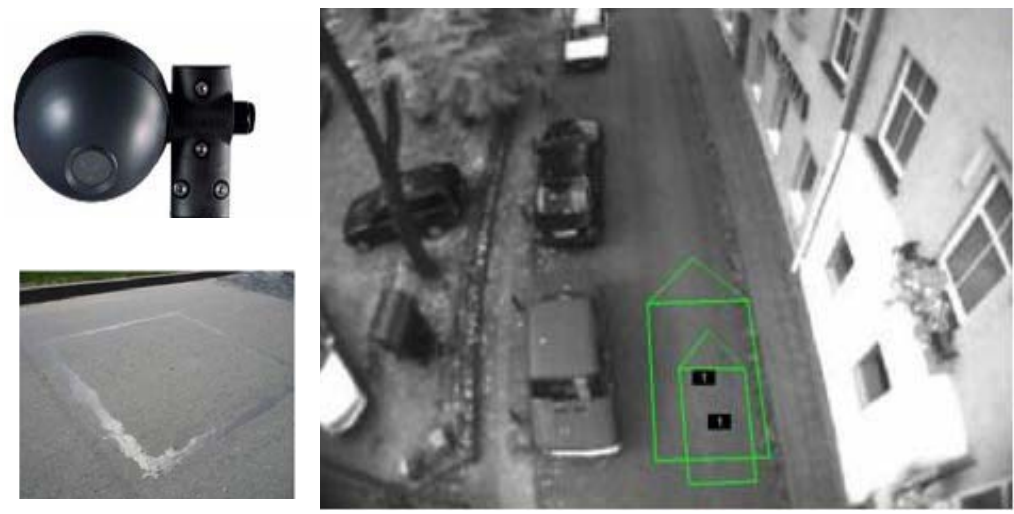

Figure 1. Induction and video sensors and the surveillance area of a video sensor

\section{The Analysis of Traffic Intensity in Ukmergès and Geležinio Vilko Streets in Vilnius}

According to the statistical data, the intersection of Ukmergès and Geležinio Vilko Streets (see Figure 2) is most congested in all directions in the morning peak hours (from 7:00 to 10:00) because the dormitory suburbs' inhabitants are travelling towards the places of their work (in the centre). In the evening peak hours, the junction load is higher only on Geležinio Vilko roadway (in both directions) because a large traffic flow is going from Geležinio Vilko to Ukmergès Street through the intersection overpass where traffic is moving without stopping.

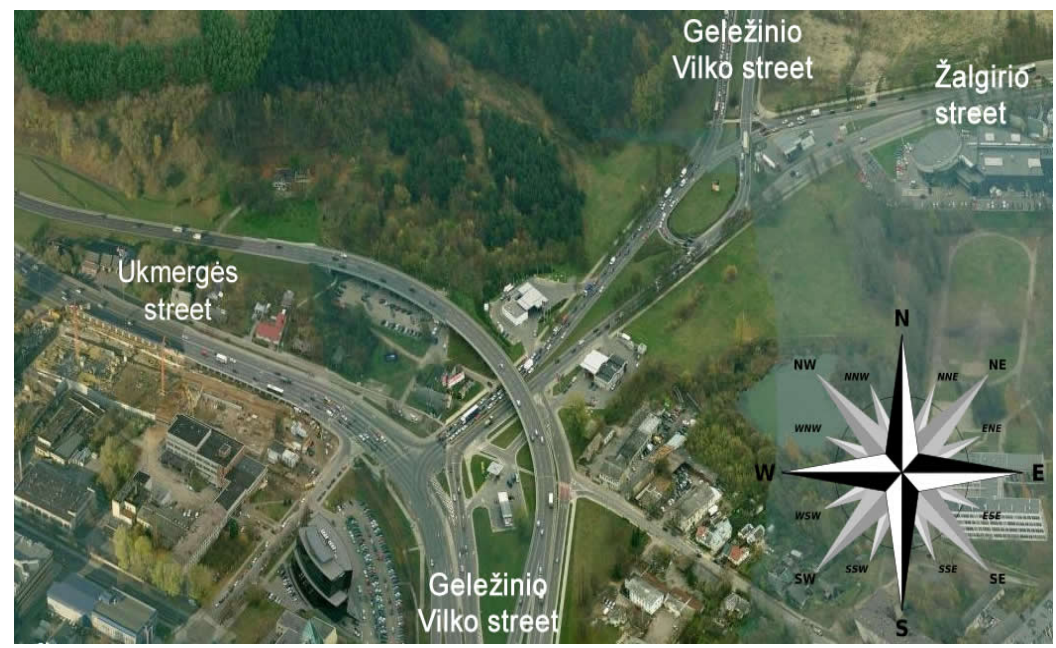

Figure 2. The intersection of Geležinio Vilko and Ukmergès Streets 
According to the statistical data (see Figure 3), the highest load on Geležinio Vilko roadway from the north-east direction was recorded on Thursday, 2011-11-08, and made 2445 vehicles per hour. In Fig. 3 , we can see that this intersection is overcrowded with traffic all day long. Therefore, we can say that the measuring data are wrong, and the real load at this intersection is higher. It should be the same as the backward direction flow in the evening.

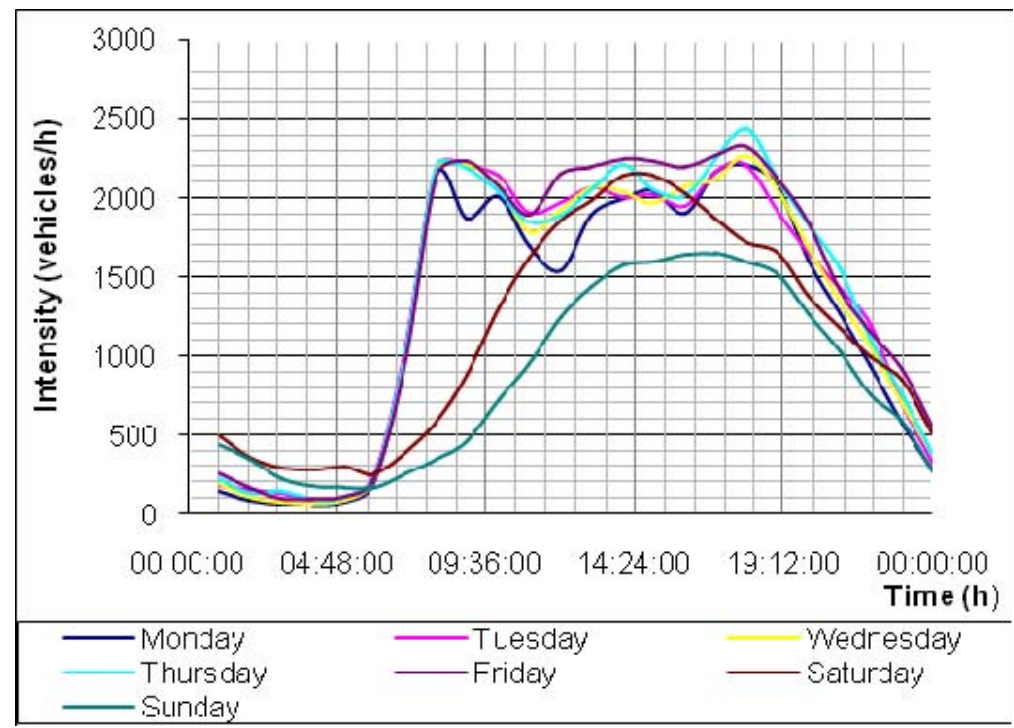

Figure 3. The intensity of traffic at the intersection of Ukmergès and Geležinio Vilko Streets in the direction from north to east

More heavy traffic is registered at the intersection in the southern direction in Geležinio Vilko Street. In this direction, according to the statistical data, the maximum traffic intensity during the morning and evening peak hours is more than 5000 vehicles per hour (see Figure 4). The maximum intensity, reaching 5,510 vehicles per hour, was recorded on Friday (2011-11-09). In the graph, traffic intensity in the morning and evening rush hours is demonstrated. The first and the second graphs show that there is a large automotive traffic exchange between the southern and north-eastern sides of Geležinio Vilko Street.

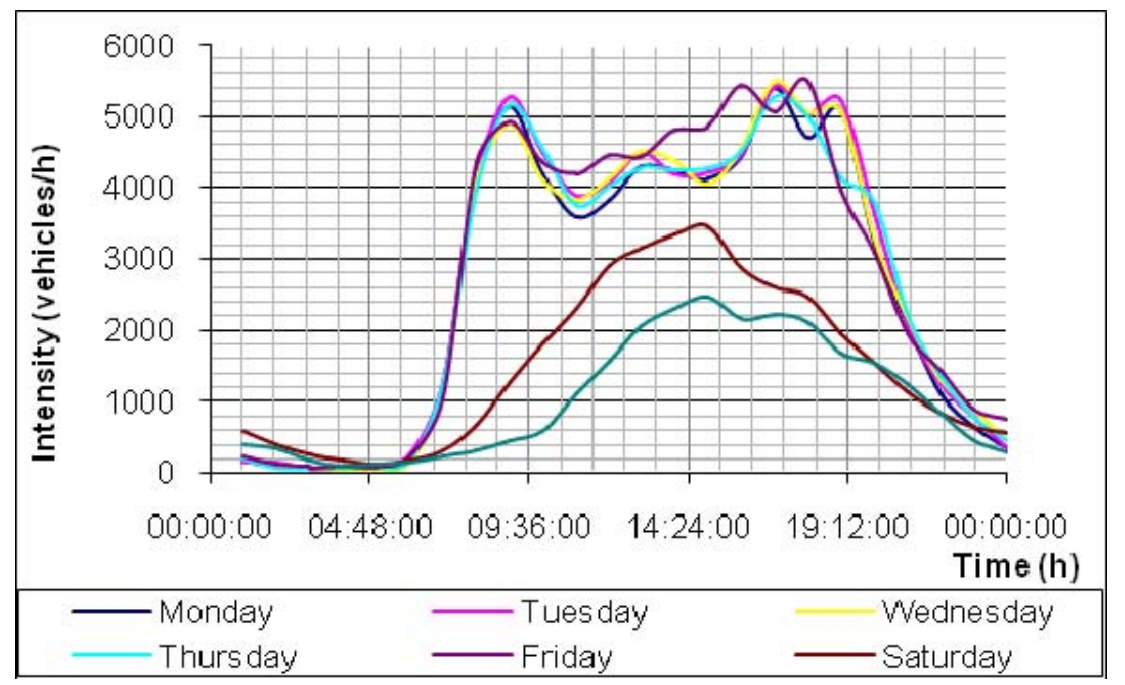

Figure 4. The intensity of traffic at the intersection of Ukmergès and Geležinio Vilko Streets in the north-east direction

The differences in traffic between Ukmergès and Geležinio Vilko Streets are shown on Figure 5. We see only the morning rush hour traffic, when vehicles travel from Ukmergès Street towards Geležinio Vilko Street in the southern direction because the vehicles going in the backwards direction use the overpass and can move without stopping. Therefore, they do increase traffic at the intersection. 


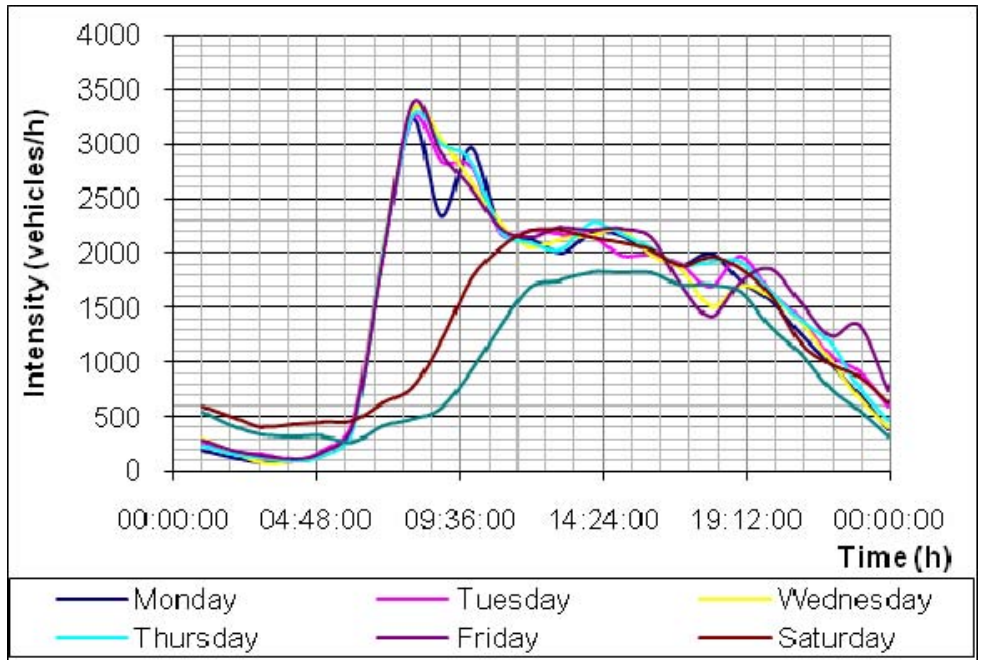

Figure 5. The intensity of traffic at the intersection of Ukmergès and Geležinio Vilko Streets in the north-west direction

The maximum intensity in Ukmergès Street in the southern direction is close to 3500 vehicles per hour (more exactly, 3371 vehicles per hour). The highest traffic intensity was recorded on Friday (2011-11-09). After the morning peak, the intensity decreased, and after 4 p.m. it did not exceed 2000 vehicles per hour.

\section{Intersection and Free Flow Capacity}

In SimTraffic 7 program, an intersection can be assessed according to the so-called ICU (intersection, capacity, usage) rate. The application, operating principle and method of ICU in SimTraffic 7 program are described by David Husch and John Albeck in their book "Intersection Capacity Utilization Evaluation Procedures for Intersections and Interchanges" (David Husch, John Albeck 2003). ICU is an indicator of the reserve capacity and congestion of the intersection. This method cannot determine the delay time, but it can be used for determining how often the intersection will be congested. Thus,

$I C U=\left(v / s \cdot C L+t L_{i}\right) / C L$,

$t L=\min \left(4 s, 2 s+\frac{D}{s p}, Y+A R\right)$,

where $C L$ is standard cycle time (120 seconds); $t L_{i}$ is the lost time; $v / s$ is the volume to saturated flow ratio; $D$ is intersection length; $s p$ is speed; $Y$ is yellow time $(3,5 \mathrm{~s}) ; A R$ is red time $(0,5 \mathrm{~s})$.

The lost time $(t L)$ minimum value of urban intersections is up to 4 seconds. Two seconds should be added to the crossing time at the junction to get the lost time value:

The total saturated flow rate (s) is the adjusted saturated flow rate:

$s=i \cdot n \cdot f L U \cdot f T$,

$f T L=0.95 ; f T R=0.85$;

$f T T=(1-0.15 \cdot(v R-v C R)(v C T)) \cdot\left(1-0.05 \cdot \frac{v L-v C L}{v C T}\right)$,

$v C T=v T+v R *+v L * *$

$v C L=v L, v C R=v R$,

where $f L U$ is the lane utilization factor; $f T$ is the criterion of turning evaluation; $i$ is the ideal flow; $n$ is the lane volume; $\mathrm{T}$ is a through pass; $\mathrm{R}$ is a right turn; $\mathrm{L}$ is a left turn; $v C$ is the total intensity; $*$ add $v R$ 
to $v C T$, when $n R=0$, else add $v R$ to $v C R$. **add $v L$ to $v C T$, when there is a free left-through lane, else add $v L$ to $v C L$.

The criterion of turning evaluation $(f T)$ is used in regulating the volume of the right- and leftturn movements on the lanes in the lane group.

Lane utilization factor $(f L U)$ is used for regulating the saturated flow, when there are two or more lanes. This amendment will help evaluate the use of different lanes (see Table 1).

Table 1. Lane utilization factor

\begin{tabular}{|l|l|l|l|}
\hline Number of lanes & Left & Through & Right \\
\hline 1 & 1.0 & 1.0 & 1.0 \\
\hline 2 & 0.971 & 0.952 & 0.885 \\
\hline 3 and more & 0.971 & 0.908 & 0.885 \\
\hline
\end{tabular}

If the intersection is fully loaded (ICU is $100 \%$ ), the intersection capacity dependence on the number of traffic lanes (see Figure6) can be obtained as follows:

$v=s \cdot(I C U \cdot C L-t L) / C L$.

To describe the free flow, we can use one of the models, for example, the Greenberg's model for one-lane road, where the flow velocity depends on the maximum density $p$ max (the number of vehicles per kilometre of road), the free movement velocity $V f$ and nominal density $p$ (Pushkin Kachroo 2007).

$V=V f \cdot \ln \left(\frac{p \max }{p}\right)$

The maximum density of one kilometre road is 200 vehicles $/ \mathrm{km}$, while free movement velocity was selected according to the 'slowest' road section (with the speed of $70 \mathrm{~km} / \mathrm{h}$ ). Using these data, the dependence of the velocity on density can be obtained.

The capacity $Q$ depends on the density $p$ and the velocity $V$ :

$Q=V \cdot p$

We can use this formula to obtain the capacity dependence on the velocity (see Figure 7) and density (see Figure 8).

Thus, the maximum capacity of one lane (where the speed is $50-60 \mathrm{~km} / \mathrm{h}$ ) reaches 5000 vehicles per hour, when traffic density is about 75 cars per hour. Meanwhile, two-lane intersection capacity is only 3,000 cars per hour.

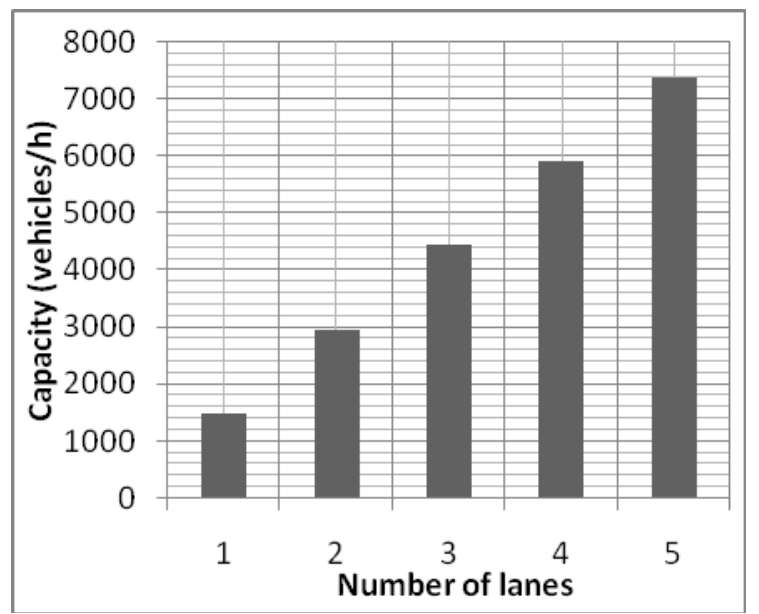

Figure 6. The dependence of intersection capacity on the number of lanes 


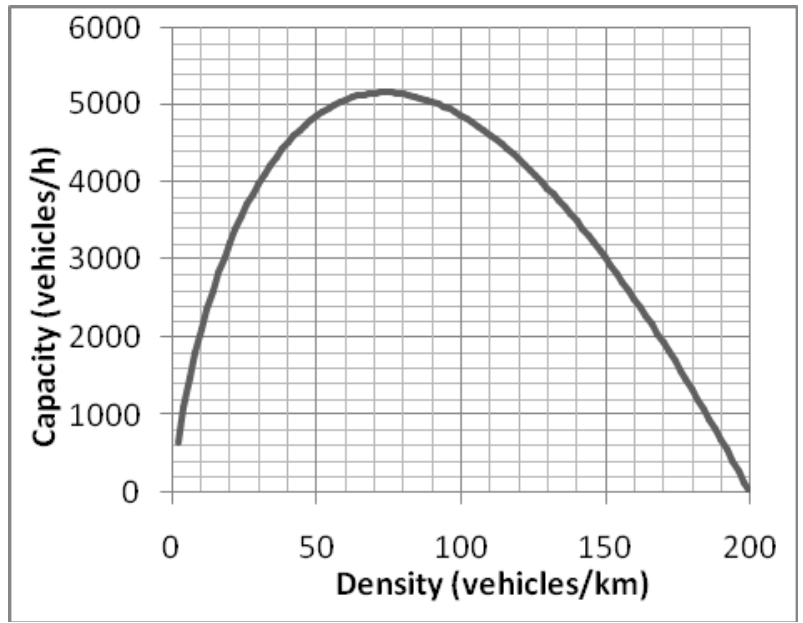

Figure 7. The dependence of the capacity on density

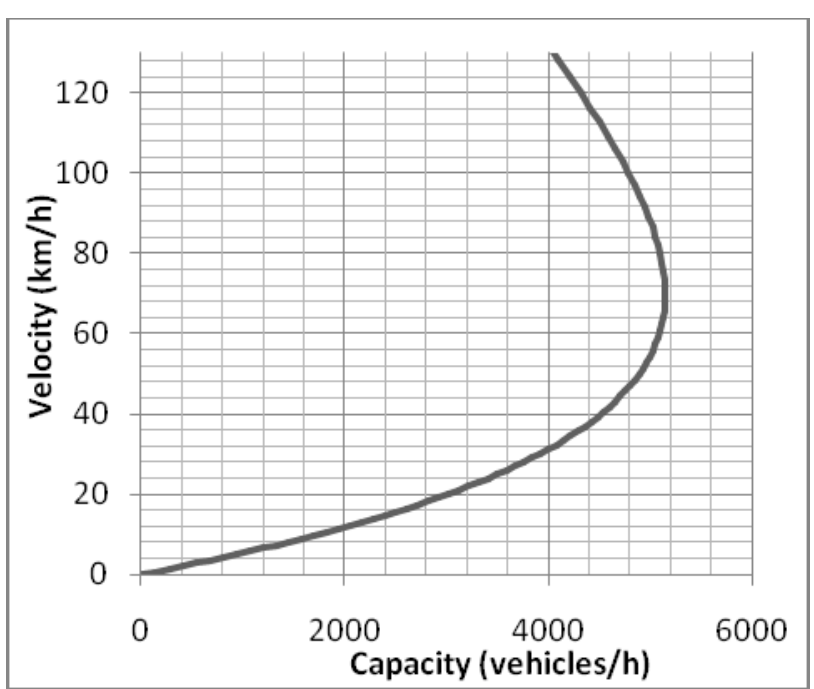

Figure 8 . The dependence of the capacity on velocity

\section{Traffic Modifications in Ukmergès and Geležinio Vilko Streets in Vilnius}

To increase traffic capacity at this point we suggest:

- To reduce the number of intersections controlled by traffic lights.

- To install pedestrian underpasses.

- To install an engineering tool "guardrail", not allowing the drivers of the Geležinio Vilko Street (north-east) to turn right and mix with the flow, coming from Ukmergès Street from the north.

- To reduce the number of lanes from 4 to 2 at the entrance from Ukmergès to Geležinio Vilko Street.

- To provide all possible additional tools for ensuring the continuous traffic(to make the lanes wider on the turns).

Flows are separated, therefore, the vehicles coming to the intersection can move unobstructed. The pedestrians are also separated from the flow of vehicles. For each flow, there is a two-lane way (see Figure 10), where an ideal traffic flow can consist of up to 4000 vehicles/h, and the maximum capacity is twice as high as the ideal capacity. To make the flow continuous, the turn from Žalgirio to Geležinio Vilko Street in the south-west direction and the turn from Geležinio Vilko to Žalgirio Street in the eastern direction are prohibited. Drivers will use the nearby streets (Ukmergès and Kalvarijų), the entrance to which is continuous. To facilitate the access from Žalgirio to Geležinio Vilko Street in the northern direction an acceleration lane should be added (see Figure 10). 
The intersection safety can be described by the number of moving paths' intersection or the number of the conflict points. The smaller a number of the conflict points is - the safer the intersection. The conflict points for the selected nodes were determined before and after modification. Before the modifications have been made at the intersection of Geležinio Vilko and Ukmergès Streets, the number of conflict points reached 42 (see Figure 9), with 30 of them referring to vehicles, and 12 concerning the vehicles and pedestrians. After the modifications have been made, the number of conflict points decreased to only one point (see Figure 10) due to the reduction of the number of lanes, flow separation and installation of the pedestrian underpasses.

Before the modification of the Geležinio Vilko and Žalgirio Streets' intersection, the number of the conflict points reached 21 (see Figure 9), with 16 referring to vehicles, and 5 concerning the vehicles and pedestrians. After modification, the number of the conflict points decreased to 2 points (see Figure 10). The total number of the conflict points decreased from 63 to 3 points, which means the reduction by 21 times.

When the velocity on the road decreases, it means that the traffic situation becomes complicated and the congestion is inevitable.

The average velocity on the considered road was rather low in the rush hours (see Figure 11). After modification, the average velocity has grown considerably (see Figure 12).

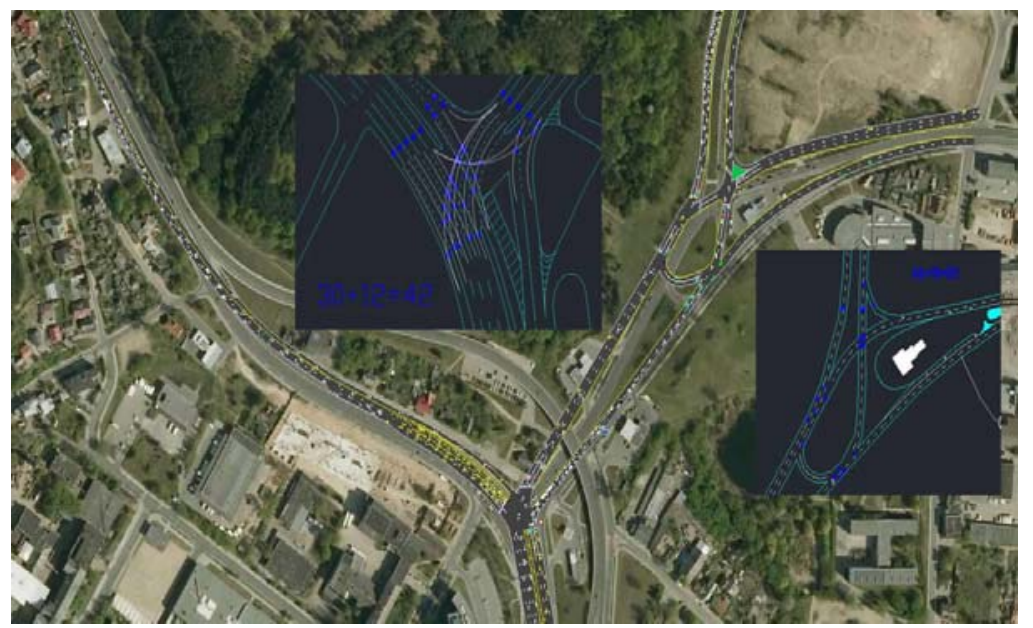

Figure 9. The intersection of Ukmergès and Geležinio Vilko Streets with real traffic congestion before modification

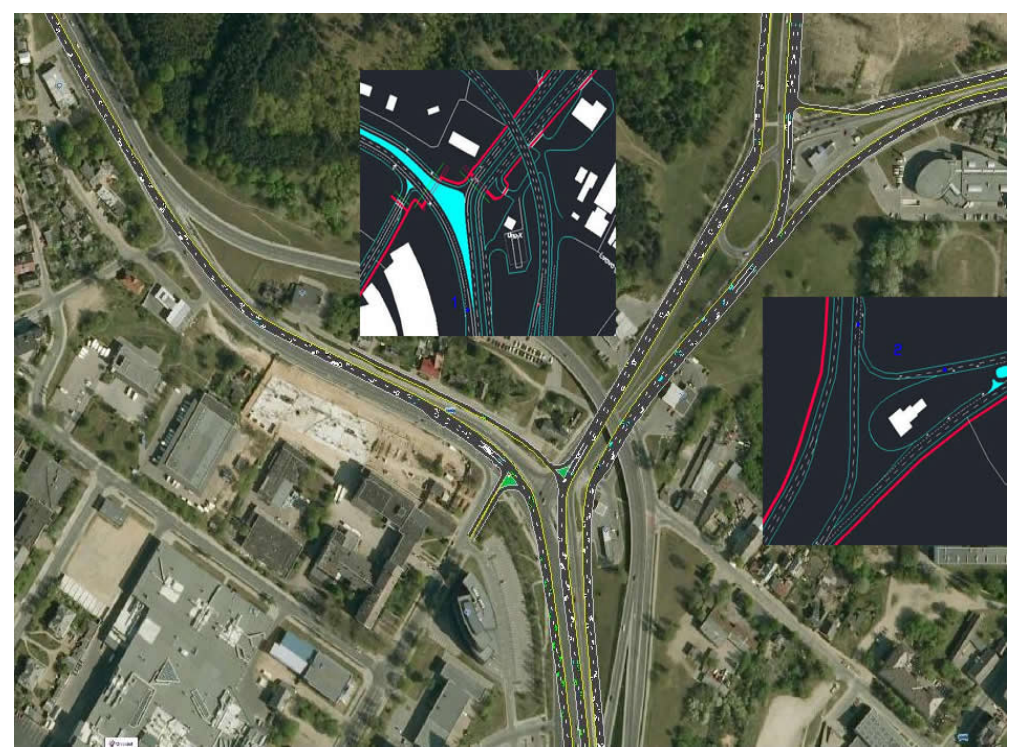

Figure 10. The intersection of Ukmergès and Geležinio Vilko Streets with real rush hour traffic intensity after modification 


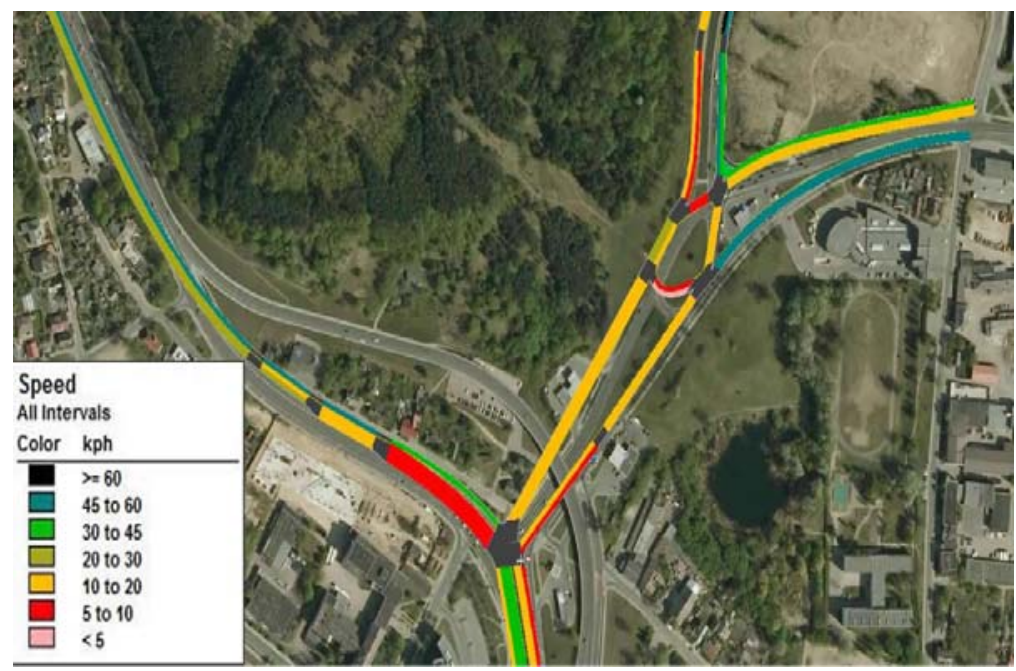

Figure 11. Average velocity before modification

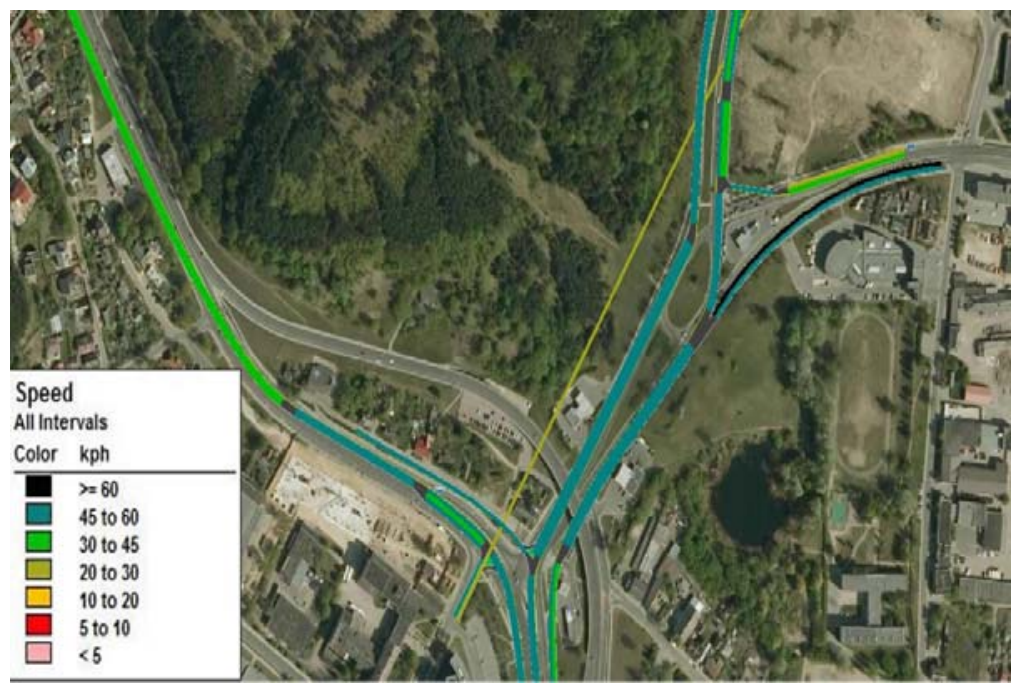

Figure 12. Average velocity after modification

\section{Conclusions}

1. In order that the traffic would be organized properly, modifications should be proposed in the context to the streets category. Effective organization of traffic can be achieved only through a traffic simulation programs.

2. Making some engineering modifications will help to ease congestion on the road. The trajectories of the flows will intersect more rarely because the pedestrians will cross traffic lanes at different levels. This will increase the road safety. The traffic will be uninterrupted that will make a positive effect on the ecology of the street. The offered solutions will help to solve the problems on the particular road section, and also will provide the increasing of traffic in the future. The traffic will be continuous even if the traffic intensity at this intersection increases more than twice.

3. The main limitations to these solutions are associated with the prohibition of movement in some directions because the left turns will be prohibited. Therefore, to reach the selected point, the drivers will search for another way, which in some cases could be longer.

\section{References}

1. Kerner, B. S. (2002). Synchronized Flow as a New Traffic Phase and Related Problems for Traffic Flow Modelling. Mathematical and Computer Modelling, 35, 481-508. 
2. Husch, D., Albeck, J. (2003). Intersection Capacity Utilization Evaluation Procedures for Intersections and Interchanges. Trafficware.

3. Mitsakis, E., Salanova, J.M., Giannopoulos, G. (2011). Combined dynamic traffic assignment and urban traffic control. Procedia Social and Behavioral Sciences, 20, 427-43.

Doi:10.1016/j.sbspro.2011.08.049

4. Kotusevski, G., Hawick, K.A. (2009). A Review of Traffic Simulation Software. Computer Science. Institute of Information and Mathematical Sciences, Massey University.

5. Lee, J., Park, B.B. (2012). Determining Lane Use Distributions Using Basic Freeway Segment Density Measures. Journal of Transportation Engineering.

Doi:10.1061/(ASCE)TE.1943-5436.0000313

6. Kachroo, P. (2007). Optimal and Feedback Control for Hyperbolic Conservation Laws Blacksburg. Virginia.

7. Xin Pei, S. C. Wong, Y. C. Li, N. N. Sze. (2011). Full Bayesian Method for the Development of Speed Models. Journal of Transportation Engineering.

Doi:10.1061/(ASCE)TE.1943-5436.0000428

8. Zi-You Gao, Ke-Ping Li, Xin-Gang Li, Hai-Jun Huang, Bao-Hua Mao, Jian-Feng Zheng. (2007). Scaling laws of the network flow. Physica A, 380, 577-584.

Doi:10.1016/j.physa.2007.02.036 